\title{
CAUTION! Transitions ahead: politics, practice and sustainable transition management
}

\author{
Elizabeth Shove* and Gordon Walker** \\ Department of Sociology* and Department of Geography**, Lancaster \\ University, Lancaster, LA1 4YD \\ E.Shove@lancaster.ac.uk
}

"The critique of the inanities and injustices of present society, however obvious they may be, is disqualified by a simple reminder that remaking society by design may only make it worse than it was. Alternative ends are invalidated on the strength of the proved ineffectuality of means" (Bauman 1991; 269)

Green (2006) is not alone in contending that "environmental 'crises' require fundamental changes in the socio-technological structure of the way we live and work". For those concerned with sustainability, the idea of transition - of substantial change and movement from one state to another - has powerful normative attractions. If 'we' can steer change, shape future development and manage movement in desired directions, perhaps 'we' can make the environment a better and more sustainable place in which to live. But how so to do? In a manifestly complex world dominated by hegemonic ideologies of neoliberal capitalism, global finance and commodity flows is it really possible to intervene and deliberately shift technologies, practices and social arrangements - not to mention their systemic interaction and interdependencies - on to an altogether different, altogether more sustainable track?

Across the board there is growing recognition of the holistic, unavoidably interrelated nature of contemporary environmental problems and of the need for fresh approaches and forms of governance capable of engaging with complex challenges of this kind. Theories and models of sustainable transition management (STM), derived from a blend of academic traditions in innovation, history and technology, appear to fit this bill and it is no wonder that they are now catching on across a number of policy domains.

In the Netherlands, government sponsored programmes have explicitly adopted methods of 'transition management' (Kemp and Loorbach 2006) and in the UK, the policy relevance of similar theories and methods is being explored and actively promoted through projects and events like those supported by the ESRC's Sustainable Technologies Programme. Academically, and in just a few years, there has been rapid growth in the 'transition management' literature and in the appeal of approaches characterised by an alluring combination of agency, complexity, uncertainty and optimism.

We do not intend to provide a thorough review or critique of what is in any case a burgeoning and quickly evolving literature, but at a time when the notion of transition management is capturing so much attention it is as well to reflect on the distinctive features of this particular policy innovation. With this 
limited aim in mind, we offer some cautionary comments and identify a handful of questions that deserve more explicit attention.

The notion of transition is firmly rooted in traditions of system thinking which highlight the co-evolution of the social and the technical and which seek to understand and analyse the emergence, transformation and decay of sociotechnical systems. Much of the 'systems in transition' literature makes use of Rip and Kemp's (1998) 'multi-level' model of innovation which distinguishes between the macro level of the sociotechnical landscape, the meso level regime and the micro level niche. The key idea is that change takes place through processes of co-evolution and mutual adaptation within and between these layers. The multi-level model can therefore be used to describe how new technologies emerge within more or less protected niches, and how they become 'working' configurations that shape and re-shape the regimes and landscapes they sustain and that are in turn sustained by them. In terms of transition, the core task is to figure out how currently dominant sociotechnical regimes might be dislodged and replaced and how new configurations might become mainstream.

Following this line of enquiry, the systems in transition literature has sought to conceptualise system dynamics, often through retrospective analyses of the rise and fall of selected sociotechnical systems and regimes (e.g. from sail to steam ships, from horse to car, or from coal to gas (Geels 2002; Correlje and Verbong 2004). In literature of this kind, there is no assumption that better understanding will necessarily enhance the capacity to manage. This is to be expected in that the challenge is to understand the co-evolution of complex systems in which the role of self-styled systems builders is necessarily constrained and in which the outcome of deliberate intervention is inherently unpredictable. One consequence is that studies of systems in transition are typically distanced, even voyeuristic, making few claims about how individuals and organisations can, might or should act to affect the processes in question or to steer trajectories towards pre-defined, normative goals.

In contrast, proponents of transition management (Rotmans et. al. 2001; Smith et. al. 2005; Kemp and Loorbach 2006), subscribe to models of agency and intervention not always shared by the commentators and systems literature on which they draw. There are relevant differences of opinion, for instance, about whether transition management is a matter of picking one trajectory or another - Kemp, for example, refers to routes that diverge in the forest $^{1}$ - of agents shaping or making niches and paths (Berkhout et. al. 2004: 50 ), or of managing critical processes of selection and variation within a broader dynamic of sociotechnical evolution. Whatever the conclusion on this point, most recommend the deployment of multiple methods and tools for intervention, also arguing for processes of governance (rather than government), for the involvement of diverse actors and knowledges, and for explicit recognition of the uncertainties and limitations of science-based expertise. These strategies allow that managing systems involves 'extremely complex processes' (Elsen and Wieczorek 2005: 655) that are multi-actor,

\footnotetext{
${ }^{1}$ http://kemp.unu-merit.nl/docs/Transition\%20management\%20for\%20SD3.doc (29.9.06)
} 
multi-factor and multi-level. However novel and complex the challenge might be, the main point is that very idea of transition management supposes that deliberate intervention in pursuit of specific goals, like those of sustainability, is possible and potentially effective.

Differences between analyses of systems in transition and models of transition management are not only about representations of power or interpretations of just how many 'invisible' hands are involved (Rip and Groen 2001 ), they also have to do with the role and status of critical junctures, and the possibility of anticipating turning points and moments when strategic nudging has the potential to change the trajectory of even complex and embedded systems. It is around these themes that our cautionary comments revolve.

\section{Caution 1. Transition politics}

Let us imagine, at least for the next few pages, that transitions can be managed and that this is something that transition managers do. Who are these critical actors and, just as important, on what authority and on whose behalf do they act?

The very idea of deliberate transition management supposes some kind of orienting vision. In the field of environmental policy there is a tendency to assume that such an image exists and that it is defined and shared by a constituency of institutional actors who are, by implication and example, located within national or regional organisations. There is increasing interest in how societal aspirations and shared problem definitions are articulated (Kemp and Loorbach, 2006: 112) and in how transition managers might create and maintain public support over the long term (Kemp and Rotmans 2004: 151) yet the general view is that goals like those of sustainability provide a suitable target or provisionally desired destination. The practical task is then one of steering and levering events in that direction.

What are the everyday politics of such an enterprise? When and how are the goals of transition management subject to critical scrutiny, and by whom? Equally important, who wins and who loses out as transitions are guided in one direction but not another? We suggest that the normally obscure politics of transition management deserve more explicit attention on at least three counts.

First, we argue there is a politics to the very processes of abstraction involved in defining something to manage (the 'it', or system) and to the implication that there are managers of the 'it' who sit outside 'its' boundaries and who can apply management tools including levers, niche-building machinery, and engineering devices from a privileged, knowledgeable and above all, external position. The process of abstracting the 'it' in question - the policy, the goal, the system - from its historical and contemporary environment is not just a technical matter of analysis but a political, constructed and potentially contested exercise in problem formulation. By way of illustration, Geels suggests that the transition from cesspools to sewer systems depended upon 
a process of agenda setting in which specific concepts of hygiene and epidemiology acquired political power (Geels 2006).

Furthermore any truly systemic analysis cannot exclude actors who are cast as managers from the systems in which they seek to intervene and of which they are a part. Again this is not simply a matter of positioning: being part of a system necessarily limits actors' capacities to conceive and understand the dynamics of the whole. As Rip (2006) argues 'steering from within' is unavoidably myopic. Apparent successes are therefore as likely to reflect the local repair work required to keep things going as the quality of anticipatory knowledge deployed by individuals and organisations that harbour illusions of their own management agency.

Second, new kinds of research and analysis are required to articulate the complex, multiple and always contested commitments that go into making future visions toward which transitions are directed. Social scientists are now used to critiquing science-based assessments of environmental impact, but what more is involved in evaluating the cultural and political assumptions and institutional side effects of transition management? This is a distinctly challenging task and one that should, at a minimum, involve careful scrutiny of the historical evolution of guiding images and ideals, of their circulation across different social and spatial scales, and of resistances to them. Transition managers' efforts to develop and work towards shared societal or environmental goals are all very well but techniques like those of multistakeholder involvement in foresight exercises, or methods of public participation and deliberation are never 'neutral' and never evacuated of power and strategic behaviour (Bickerstaff and Walker 2006). Initiatives of this kind can be experienced as processes of co-option, the effect of which is to neuter rather than embrace dissent. In addition, and in any event, it is important to remember that stakeholders' visions of the future are always and inevitably shaped by the systems and social environments they inhabit today.

Third, despite extensive debate and rhetoric about the construction and democratic choice of visions and images of the future, the depth of the politics involved is frequently underplayed. Certain socio-technical systems may be viewed as unproblematically desirable elements in an equally consensual, equally unproblematic interpretation of sustainability, but others - such as the 'sustainable' nuclear based energy infrastructure currently advocated in the UK - are clearly not. Advocates of sustainable transition management do not always appreciate the deep ambivalence of sustainability as a category and its power as legitimising discourse. For example, Kemp and Loorbach (2006: 15), argue for strategies designed to promote 'transitions towards more environmentally and socially benign societal systems'. It is perhaps possible to imagine some shared, technically determined specification of environmentally 'benign', but by what means might a more socially benign societal system be identified? For whom is the system more benign, by whose measure and across what space and scale? Even the most primitive attempt to establish starting assumptions (for example, does benign mean being more equal?) would immediately reveal divisions and fractures between opposing interests and ideologies. Fundamental conflicts of this kind rarely figure in the 
rather ordered and consensual world presented by much of the transition management literature, this being a world in which 'interactive strategy development' appears both possible and plausible.

In sum, it is necessary to recognise that provisional templates for transition are political statements that can only be partially inclusive (when there are ever more actors on the social stage), contingent (when conditions are dynamic) and potentially unstable as material forms and practices evolve over time. In other words, there is a politics to transition management, a playing out of power of when and how to decide and when and how to intervene, which cannot be hidden beneath the temporary illusion of 'post-political' common interest claims of sustainability (Swyngedouw 2006).

Still assuming the possibility of transition management, these comments beg further questions about the work involved in re-defining and revising the goals of sustainable transition management as 'the system' evolves.

\section{Caution 2. Managing transition management}

Compared with 'normal' modernist policy makers, transition managers are explicitly aware of the fact that they are handling complex problems and uncertain processes involving multiple, multi-level stakeholders. They are also aware that they are caught up in a cycle of problem-definition, intervention and response. Such complexities are to some degree accommodated in the framework of 'reflexive governance', this being a discourse and an approach that acknowledges and responds to the processes of globalisation and that recognises the increasing extent and range of actors involved in the organisation of daily life. A system orientation, when combined with ideas of reflexive governance, implies not one moment of intervention, following which managers stand back and await the desired result, but a constant, continual dynamic in which further adjustments are required as environmental conditions change, these changes being, in part, the outcome of previous interventions. Feedback, monitoring and circuits of action and reaction are integral to this overall scheme.

As Smith et. al. suggest, this calls for a new breed of managers schooled in the arts of transition. In their words, 'The art of governing transitions becomes one of recognising which context for transformation prevails, and which drivers offer the best leverage for guiding change in a desirable direction' (Smith et. al. 2005: 1498).

But what of the details? What are the new institutions of reflexively governed transition management, and what are the mechanisms through which goals are to be reinvented and revised in the light of events? More pragmatically, what is to be monitored (and thus form the basis for reflection and review), how frequently should this monitoring go on, and on what scale? How are transition managers to identify the early signs of trajectories that take decades to unfold (Geels and Kemp 2006), and how should they respond when relevant dynamic processes speed up or slow down? 
These questions imply that reflexively governed sustainable transition management (RGSTM) is an entirely new beast. Not all commentators agree. For example, Kemp and Rotmans make the point that 'transition management does not call for an upheaval in policy instruments' (2004: 152), and Smith et al (2005) similarly write about a familiar repertoire of taxes, regulation and assorted incentives variously deployed in different transition situations. Thoroughly systemic, thoroughly co-evolutionary models of social and environmental change undoubtedly challenge conventional approaches to problems of sustainability. In so far as they embody these ideas, strategies of transition management imply a necessarily radical overhauling of theory and orientation, but our caution is that such techniques can also be incorporated into political business-as-usual, albeit with a little more frequent revisiting of goals and a somewhat longer term horizon.

Setting these issues of politics and agency aside, but still temporarily believing in the possibility of transition management, we now comment on two rather different questions, both of which deserve further attention.

\section{Caution 3: Missing Transitions}

Models of transition management generally, but tacitly, suppose that the key task is to support and stimulate transitions that are heading in the 'right' and therefore more sustainable direction. Arguably equally important and largely neglected in the management literature are those transitions which appear to be heading in exactly the opposite direction, which emerge from the left field, 'managed' by actors whose interests are not part of the consensus vision and whose 'malignant' priorities lie elsewhere. The spread of air conditioning across cultures and continents previously immune to the normalised 'requirement' for mechanical cooling is one such example (Chappells and Shove 2005); the imminent arrival on European shores of the all singing and dancing, but distinctly resource intensive, 'Japanese paperless toilet' complete with seat warmer, deoderiser, bottom washer and dryer is another. How should those concerned with sustainability respond to the increasingly rapid, powerful and expertly orchestrated diffusion of unsustainable technologies, practices and images? Is the subtle modulation of reflexive governance capable of stemming and diverting unforeseen transitions of this kind, or are more robust counter measures required?

A more comprehensively systemic approach would, of course, attend to the co-evolving dynamics of air-conditioning in relation to passive cooling and to changing concepts of comfort, and would take note of the relation between competing systems and practices. It would also offer an equally detailed analysis of processes that parallel those of innovation, these being trajectories of erosion, decay and fossilisation. Socio-paleontology - the study of disappearing systems and practices - has yet to be developed on any scale and for the time being, theories of innovation dominate the field. It is, however, clear that transitions of any description routinely involve and require the loss or abandonment of previously important sociotechnical systems. Although this is of interest to historians of technology, the transition 
management literature says little about how the 'death' of undesirable systems might be engineered.

\section{Caution 4: Transitions in practice}

This emphasis on innovation goes hand in hand with an also implicit focus on technical systems and infrastructures of provision and supply. Popular examples have to do with transportation systems (Elzen and Wieczorek 2005), with water infrastructures (van der Brugge et. al. 2005), or with energy and 'the emergence of new technological, institutional or cultural patterns in utility provision' (Voss et al 2006: 175). Sustainability is tacitly defined as a matter of resource management, efficiency and ecological modernisation and, again by implication, transitions in that direction require the transformation of current systems of provision. There are three points to notice about this orientation. First, and for all the talk of socio-technical co-evolution, there is almost no reference to the ways of living or to the patterns of demand implied in what remain largely technological templates for the future. Second, and because large-scale technological examples command so much attention, commentators take it for granted that policy and corporate actors are the key players - even if the involvement of other groups and interests is vital (Smith, 2006: 319). Third, the transition management literature consequently draws upon a narrow (perhaps necessarily narrow) slice of what is in fact a much wider debate about social systemic change.

The literature on innovations in practice demonstrates that manufacturers and producers are unable to control the fate and fortune of the things they make, and that consumers, far from being external to systems of innovation, are central to them (Franke and Shah, 2003; Shove and Pantzar 2005). As we have argued elsewhere (Shove 2003; Hand, Shove and Southerton 2005), the normalisation of consumer expectations like those of showering every day, and of maintaining a standardised indoor environment, all over the world, whatever the weather outside, sustain complexes of practice the successful accomplishment of which requires what are probably unsustainable patterns of demand. However important these developments might be, and however central to sustainability, transition managers rarely attend to the dynamics or to the distinctive periodicities and mechanisms of change associated with them. Nor do they have the conceptual resources with which to enter these ordinary arenas of everyday life.

\section{Concluding comments}

Faced with the possibility of transitions ahead and of a simplistic uptake of approaches and models originally rooted in the complexities of systems thinking, we suggest that caution is required.

We are wary of the notion that transition management, with its accompanying repertoire of concepts and tools, provides a neat model of how managers might intervene (albeit reflexively) to shape and modulate processes of change. We have observed that these approaches can all too easily obscure their own politics, smoothing over conflict and inequality; working with tacit 
assumptions of consensus and expecting far more than participatory processes can ever hope to deliver. We also argue that there are important types and agents of change that are missed in much of this literature. These include rampant innovations that slice through expected and desired pathways of change; trajectories of fossilisation and decay (as established sociotechnical systems are abandoned), and fundamental transformations in the ordinary routines of daily life.

For academic readers, our commentary argues for loosening the intellectual grip of 'innovation studies', for backing off from the nested, hierarchical multilevel model as the only model in town, and for exploring other social scientific, but also systemic theories of change. The more we think about the politics and practicalities of reflexive transition management, the more complex the process appears: for a policy audience, our words of caution could be read as an invitation to abandon the whole endeavour. If agency, predictability and legitimacy are as limited as we've suggested, this might be the only sensible conclusion.

However, we are with Rip (2006) in recognising the value, productivity and everyday necessity of an 'illusion of agency', and of the working expectation that a difference can be made even in the face of so much evidence to the contrary. The outcomes of actions are unknowable, the system unsteerable and the effects of deliberate intervention inherently unpredictable and, ironically, it is this that sustains concepts of agency and management. As Rip argues 'illusions are productive because they motivate action and repair work, and thus something (whatever) is achieved' (Rip 2006: 94). Situated inside the systems they seek to influence, governance actors - and actors of other kinds as well - are part of the dynamics of change: even if they cannot steer from the outside they are necessary to processes within.

This is, of course, also true of academic life. Here we are, busy critiquing and analysing transition management in the expectation that somebody somewhere is listening and maybe even taking notice. If we removed that illusion would we bother writing anything at all? Maybe we need such fictions to keep us going, and maybe - fiction or no - somewhere along the line something really does happen, but not in ways that we can anticipate or know.

\section{References}

Bauman, Z. (1991) Modernity and Ambivalence, Ithaca: Cornell University Press.

Bickerstaff, K. and Walker, G. P (2005) 'Shared visions, unholy alliances: power, governance and deliberative processes in local transport planning', Urban Studies, 42 (5):, 2123-2144.

Chappells, H., and Shove, E., (2005) 'Debating the future of comfort: environmental sustainability, energy consumption and the indoor environment' Building Research and Information 33(1): 32-40. 
Correlje, A. and Verbong, G. (2004) 'The transition from coal to gas: radical change of the Dutch gas system' in Elzen, B., Geels, F., and Green, K. (eds), System Innovation and the Transition to Sustainability: Theory, Evidence and Policy, Cheltenham: Edward Elgar.

Elzen, B. and Wieczorek, A. (2005) 'Transitions towards sustainability through system innovation' Technological Forecasting and Social Change, 72: 651-661.

Franke, N. and, Shah, S. (, 2003) '. How communities support innovative activities: an exploration of assistance and sharing among end-users'. Research Policy, 32, 157-178.

Geels, F. (2002), 'Technological Transitions as evolutionary reconfiguration processes: a multi-level perspective and case study', Research Policy, 31(8-9): 12571274.

Geels, F. (2006) 'The hygienic transition from cesspools to sewer systems (18401930): The dynamics of regime transformation', Research Policy, 35 (7): 1069-1082.

Geels, F. and Kemp, R. (2006), 'Typology of sociotechnical transition pathways: refinements and elaborations of the multi-level perspective' - forthcoming in Research Policy

Green (2006) http://www.sustainabletechnologies.ac.uk/PDF/transition/Green.pdf

Hand, M., Shove, E. and Southerton, D., (2005) 'Explaining showering: a discussion of the material, conventional and temporal dimensions of practice', Sociological Research Online, 10(2): http://www.socresonline.org.uk/10/2/hand.htm.

Kemp, R. and Loorbach, D. (2006) 'Transition Management: a reflexive governance approach', in, Voss, J-P., Bauknecht, D. and Kemp, R. (eds). Reflexive Governance for Sustainable Development, Cheltenham: Edward Elgar..

Kemp, R. and Rotmans, J. (2004) 'Managing the transition to a sustainable mobility' in Elzen, B., Geels, F., and Green, K. (eds), System Innovation and the Transition to Sustainability: Theory, Evidence and Policy, Cheltenham: Edward Elgar.

Rip, A. (2006) 'A co-evolutionary approach to reflexive governance - and its ironies', in, Voss, J-P., Bauknecht, D. and Kemp, R. (eds). Reflexive Governance for Sustainable Development, Cheltenham: Edward Elgar.

Rip, A. and Groen, A. (2001), 'Many visible hands' in Coombs, R., Green, K., Walsh, V. and Richards, A. (eds), Technology and the Market: Demands, users and innovation, Cheltenham: Edward Elgar.

Rip, A. and Kemp, R. (1998) 'Technological change' in, Rayner, S. and Malone, E. (Eds.), Human Choice and Climate Change vol. 2. Battelle: Columbus, Ohio.

Rotmans, J., Kemp, R. and van Asselt, M. (2001) 'More Evolution than Revolution. Transition Management in Public Policy', Foresight 3(1): 15-31

Shove, E. (2003), Comfort, Cleanliness and Convenience, Oxford: Berg. 
Shove, E. and Pantzar, M. (2005), 'Consumers, producers and practices: understanding the invention and reinvention of Nordic walking', Journal of Consumer Culture, 5(1): 43-64.

Smith A., Stirling, A. and Berkhout, FT. (2005) 'The governance of sustainable sociotechnical transitions', Research Policy, 34: 1491-1510.

Smith, A. (2006) 'Niche-based approaches to sustainable development: radical activists versus strategic managers', in, Voss, J-P., Bauknecht, D. and Kemp, R. (eds). Reflexive Governance for Sustainable Development, Cheltenham: Edward Elgar.

Swyngedouw, E. (2006) 'Impossible/Undesirable Sustainability and the Post-Political Condition', paper presented at the Royal Geographical Society with the Institute of British Geographers Conference, London, September 2006.

Van der Brugge, R., Rotmans, J. and Loorbach, D. (2005), 'The transition in Dutch water management', Regional Environmental Change, 5(4): 164-176.

Voss, J. P. and Kemp, R. (2005) "Reflexive governance for sustainable development - incorporating feedback in social problem solving" ESEE conference, Lisbon 14-17 June 2005.

Voss, J-P., Truffer, B. and Konrad, K. (2006) 'Sustainability foresight: reflexive governance in the transformation of utility systems', in, Voss, J-P., Bauknecht, D. and Kemp, R. (eds). Reflexive Governance for Sustainable Development, Cheltenham: Edward Elgar. 